\title{
Myelodysplastic/Myeloproliferative Neoplasm, Unclassifiable
}

National Cancer Institute

\section{Source}

National Cancer Institute. Myelodysplastic/Myeloproliferative Neoplasm, Unclassifiable. NCl Thesaurus. Code C27780.

This entity includes cases that have clinical, laboratory, and morphologic features that support the diagnosis of both a myelodysplastic syndrome and a myeloproliferative neoplasm, but do not meet the criteria for any of the other entities included in the myelodysplastic/myeloproliferative neoplasm category. (WHO, 2001) 